\title{
Conservative Management of Traumatic Tooth Fracture by Fracture Fragment Reattachment and Single Visit Nonsurgical Endodontic Treatment
}

\author{
Paromita Mazumdar
}

\begin{abstract}
Anterior crown fractures are common form of traumatic dental injuries that mainly affect the maxillary anterior teeth in children, teenagers as well as adult population. A trauma with accompanying fracture of anterior teeth is an agonizing experience for an individual requiring immediate attention, not only because of the physical disfigurement but also because of the psychological impact on the patient. Over time numerous techniques and materials have evolved for the restoration of the injured teeth, such as, resin composite with or without pin, orthodontic bands, resin crown, and ceramic crowns. Reattachment of fractured tooth fragments can provide good and long-lasting esthetics and function. Patient cooperation and understanding of the limitations of the treatment is important for good prognosis. This article reports management of complicated coronal tooth fracture treated by reattachment on tooth fragments on the palatal aspect and single visit nonsurgical endodontic treatment.
\end{abstract}

Keywords: Anterior crown fracture, Conservative treatment, Reattachment.

How to cite this article: Mazumdar P. Conservative Management of Traumatic Tooth Fracture by Fracture Fragment Reattachment and Single Visit Nonsurgical Endodontic Treatment. J Oper Dent Endod 2017;2(2):93-96.

Source of support: Nil

Conflict of interest: None

\section{BACKGROUND}

Dental trauma often has a severe impact on the social and psychological well-being of a patient. Coronal fractures represent a high proportion of the dental trauma in the permanent dentition ranging between 26 and $76 \%$ of dental injury, and approximately $16 \%$ of coronal fractures are complicated presenting pulp exposure. The reports suggest that $70 \%$ of such injuries involve the maxillary central incisors followed by maxillary lateral incisors and mandibular incisors. ${ }^{1-4}$ Depending on age, the incidence

\footnotetext{
Professor and Head

Department of Conservative Dentistry \& Endodontics, Guru Nanak Institute of Dental Sciences \& Research, Kolkata, West Bengal, India

Corresponding Author: Paromita Mazumdar, Professor and Head, Department of Conservative Dentistry \& Endodontics Guru Nanak Institute of Dental Sciences \& Research Kolkata, West Bengal, India, Phone: +913324167433, e-mail: pm.evershine@gmail.com
}

is higher in male than in female, with male: Female ratios varying from 2:1 to $3: 1 .^{5}$ Coronal fractures of permanent incisors represent 18 to $22 \%$ of all trauma to dental hard tissues, 28 to $44 \%$ being simple (enamel + dentin), and 11 to $15 \%$, complex (enamel + dentin + pulp). The main causes of trauma that affect the permanent incisors are falls, collisions, sports, violence (fights), and road traffic accidents.

Esthetic and functional rehabilitation is the primary goal of the treatment of crown-fractured tooth. A number of techniques have been developed to restore the fractured crown which ranges from simple composite resin restoration to jacket crown with acrylic resin or porcelain, orthodontic bands to stabilize the fracture fragment and also to some extent pin-retained resin restoration. An alternative approach, which is becoming more attractive due to the advancements in the field of dental adhesives, is fragment reattachment. ${ }^{6,7}$ In dentistry, teeth that were once considered irreparable after fracture and recommended for extraction can now be preserved, especially since the advent of dental adhesives. Tennery ${ }^{8}$ was the first to report the reattachment of a fractured fragment using acid-etch technique. Subsequently, Starkey and Simonsen have reported similar cases. ${ }^{9,2}$ Reattachment of fragment may offer following advantages, e.g., better esthetics and achievement of lifelike translucency, incisal edge wear at a rate similar to that of the adjacent teeth, replacement of fractured portion involving less time, positive emotional, social response, and feeling of a well-being from patient ${ }^{10}$ and last but not least, relatively inexpensive procedure.

The case report describes a step by step clinical case wherein fragment reattachment and single visit nonsurgical endodontic treatment has been performed in lieu of post core and crown or extraction.

\section{CASE REPORT}

A 38-year-old male patient reported to the clinic in the evening complaining of mobile and painful tooth after trauma to the front of the face in the afternoon.

Intraoral examination revealed that the crown of right maxillary central incisor was split into three parts on the palatal aspect (Fig. 1) but the labial surface was intact. Palatal fragments were mobile but could be apposed. Fracture line extended subgingivally on the distal surface at the palatal aspect of the tooth. 


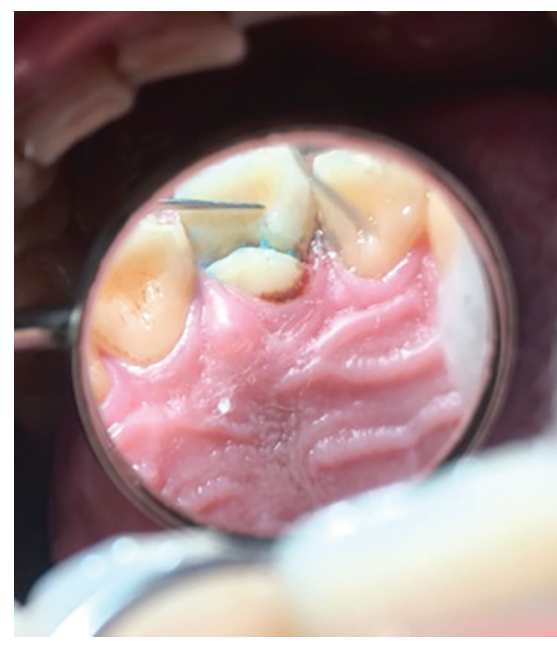

Fig. 1: Preoperative palatal view

The radiovisiography image (Fig. 2) revealed the fracture in the middle and cervical third of upper right central incisor involving enamel, dentin, and extending into pulp. Radiographic evidence revealed absence of any luxation injury, root and bone fracture. A radiograph of lower lip was taken to exclude the presence of any fracture fragment.

Treatment options presented to the patient included:

- Reattachment of the tooth fragments followed by single visit endodontic treatment,

- Removal of fractured fragments and post core and crown placement or

- Extraction of the tooth and restoration of the site with fixed partial denture or an implant-retained crown.

After some deliberation about the advantages and disadvantages of both the options, the patient decided on reattachment of the tooth fragments, as he would retain his natural tooth and other options could still be pursued should reattachment fail.

After approval of the proposed treatment plan, the fractured fragments were apposed and reattached using flowable composite resin. Etching was done with 37\% phosphoric acid for 15 seconds. The acid-etched surface was rinsed thoroughly in order to remove the acid. Excess of water was removed and the dentin surface was dried with absorbent paper. Then, the bonding agent (Scotchbond Multi-Purpose Plus, 3M ESPE, St. Paul, MN, USA) was applied with a microbrush in two coats to both the fragments, gently air thinned and light cured for 20 seconds. A polyester matrix was fitted to protect the adjacent tooth and a flowable resin (Filtek Z350 XT 3M ESPE, St. Paul, MN, USA) was used incrementally to reattach the tooth fragments. The fragment was stabilized in position and light curing was completed with light emitting diode.

Nonsurgical endodontic treatment was performed in single visit. Patient was asked to rinse with $0.2 \%$ chlorhexidine mouthwash followed by administration

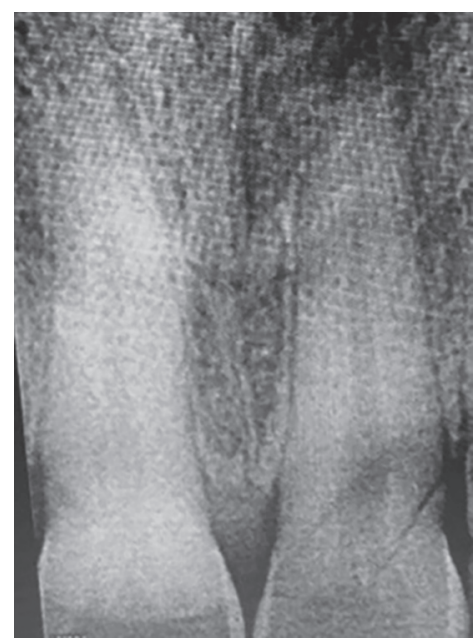

Fig. 2: Preoperative $X$-ray image

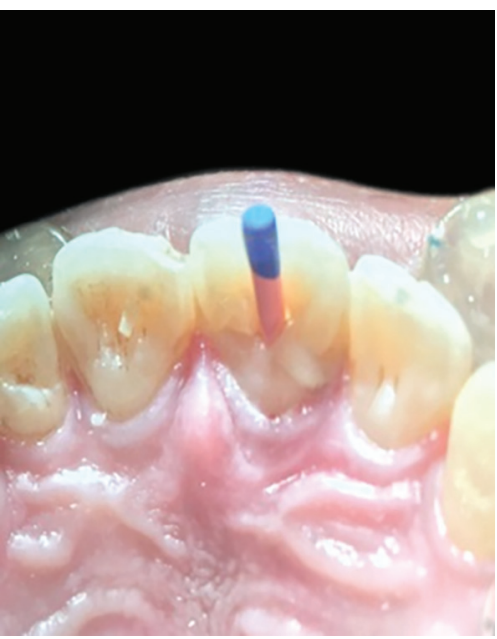

Fig. 3: Preoperative palatal view after reattacment and placement of master cone

of local anesthesia (2\% lignocaine) in buccal sulcus in relation to right maxillary lateral incisor. The tooth was isolated with cotton roll since rubber dam placement might have disintegrated the apposed fragments. Access cavity preparation was done with No. 2 round bur. Effective cleaning and shaping was carried out by rotary technique using ProTaper files according to manufacturers' instructions and intermittent copious irrigation with $1 \%$ sodium hypochlorite and normal saline. About $17 \%$ ethylenediaminetetraacetic acid (EDTA) was used to remove the smear layer and $2 \%$ chlorhexidine was used as a final rinse. Obturation was done with F3 gutta-percha with lateral compaction and glass ionomer cement (GIC) was used as sealer (Figs 3 and 4).

After the completion of obturation, the tooth was splinted with the adjacent teeth (12 and 21). The composite resin splint was polished with rubber abrasive at low speed. Occlusion was checked and adjusted using an articulating paper in the palatal surface and the patient was asked to bite in maximum intercuspal position and to make protrusive as well as lateral movement (Fig. 5). 


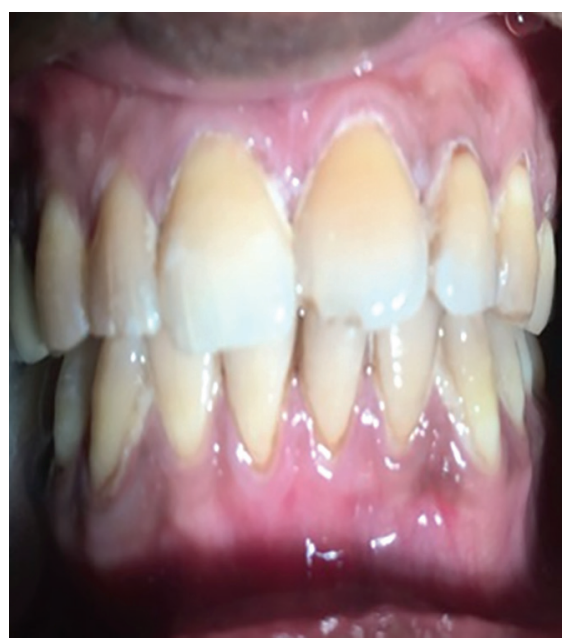

Fig. 4: Labial view of reattached fragments

Postoperatively, the patient was instructed to avoid biting into food using front teeth, exerting heavy pressure on the tooth treated, and to follow regular home care procedures relative to oral hygiene. Patient was asked to report in case of any difficulty but till after a week, there was no intimation from the patient.

\section{DISCUSSION}

Effective management of traumatic injuries has always been a challenge to the dentists. Proper diagnosis, treatment, and follow-up care are required to ensure the best possible outcome. Traumatized anterior teeth require quick functional and esthetic repair. With the advancement in the field of dental adhesives, it is now possible to achieve excellent results with reattachment of fractured tooth fragments provided that the biologic factors, materials, and techniques are logically assessed and managed. ${ }^{6,7}$ In the pre-adhesive era, fractured teeth needed to be restored either with pin retained or cast restoration that sacrificed healthy tooth structure and were a challenge for the clinicians to match with the adjacent teeth both esthetically and functionally. Whenever possible, reattachment of the fractured tooth segment is one of the best techniques for the immediate restoration of a fractured anterior tooth. ${ }^{11,12}$ It is esthetically more predictable for translucency, opalescence, fluorescence, characterizations and texture of the surface. In addition, it is less time-consuming technique compared with other direct and indirect restorations. The rate of wear is the same as that for the natural tooth while composite resin will be worn away more quickly than enamel by the opposing dentition. The use of natural tooth substance clearly eliminates the problems of differential wear of restorative material, unmatched shades and difficulty of contour and texture reproduction associated with other techniques. ${ }^{13}$ Treatment plan can be made after evaluation of the periodontal, endodontic, coronal and occlusal

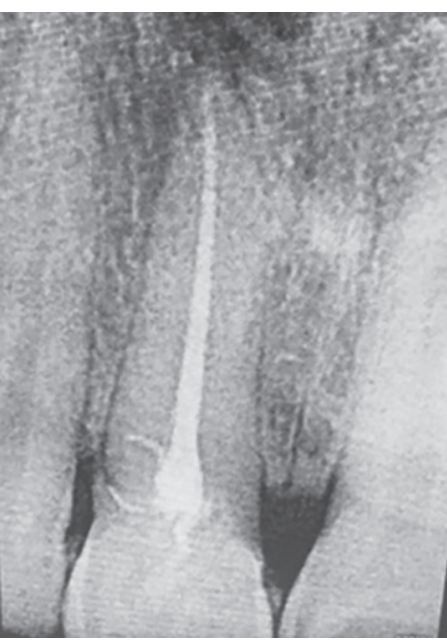

Fig. 5: Postoperative X-ray image

status. ${ }^{14}$ Other factors that might influence the choice of technique include the need for endodontic therapy, extension of fracture, quality of fit between fragments and the fracture pattern.

Studies have reported that about one out of every four persons under age of 18 will sustain a traumatic dental injury in the form of an anterior crown fracture. ${ }^{15-17}$ Fracture lines seen in crown-root fractures can be single or multiple and commonly seen in horizontal direction. A rare type of injury is a vertical fracture of crown-root running along the long axis of the tooth or deviating in a mesial or distal aspect. ${ }^{18,19}$ The traditional approach in restoring a crown-root fracture is by using cast post or prefabricated post and a core buildup but this procedure has numerous disadvantages. Also extraction followed by immediate implant placement is another option. These approaches turn out to be time-consuming, elaborate and not very cost-effective. ${ }^{20,21}$

As the reattachment procedure does not preclude any future treatment, whenever an intact fragment is available, reattachment of fractured fragment should be considered as a viable first treatment option. ${ }^{22}$ Although the application of rubber dam for the purpose of isolation provides an environment conducive to quality adhesive dentistry, but in this case, it was not to be used because the base of the fracture line was subgingival and the application of rubber dam clamp would have lead to excessive uncontrolled bleeding from the soft tissues, hence other means of isolation, such as cotton rolls, $2 \times 2$ gauze and high vacuum suction was used.

Sodium hypochlorite was used as the main irrigant as it has got the unique capacity to dissolve vital as well as necrotic pulp tissue. Ethylenediaminetetraacetic acid was used to remove the smear layer. Chlorhexidine as a final rinse was used because of its excellent antibacterial effect, its substantivity and its relatively low toxicity compared to other agents. 
Gutta-percha corresponding to F2 ProTaper file and GIC was used as core obturating material and as sealer respectively as minimal preparation of root canal space was done and additional preparation for post was not required with this technique. Flowable composite resin was used along with composite resin to fill up access cavity as it reinforces the tooth, helps in achieving higher bond strengths, and minimizes the inclusion of air voids. ${ }^{23}$

The pulp chamber was used for increasing the surface area for composite resin bonding and without the use of post. Amir et al ${ }^{24}$ showed that when endodontic therapy is required, the space provided by pulp chamber might be used as an inner reinforcement, thus avoiding any excess preparation of teeth.

CMC Taguchi et $\mathrm{al}^{25}$ reported a case on tooth fragment reattachment by using dual cure resin cement. In this case, the patient was recalled at regular intervals and healing was monitored both clinically and radiographically.

\section{CONCLUSION}

In this case report endodontic treatment of the traumatized tooth followed by reattachment of the tooth fragment proved to be effective as it restored form, function and esthetics in single visit and patient was asymptomatic both clinically and radio-graphically during the follow-up period. However, further long-term evaluation is necessary to advocate such treatment methods with predictive success rates.

\section{REFERENCES}

1. Bakland LK. Endodontic considerations in dental trauma. In: Ingle JI, Bakland LK, editors. Endodontics. 5th ed. Hamilton, Ontario: BC Decker Inc; 2002. p. 795-843.

2. Simnosen RJ. Restoration of a fractured central incisor using original tooth fragment. J Am Dent Assoc 1982 Oct;105(4): 646-648.

3. Galea H. An investigation of dental injuries treated in an acute care general hospital. J Am Dent Assoc 1984 Sep;109(3): 434-438.

4. Oztan MD, Sonat B. Repair of untreated horizontal root fractures: two case reports. Dent Traumatol 2001 Oct;17(5):240-243.

5. Ellis RG, Davey KW. The classification and treatment of injuries to the teeth of children. 5th ed. Chicago, Ill, USA: Year Book Medical; 1970. p.1-232.

6. Olsburgh S, Jacoby T, Krejci I. Crown fractures in the permanent dentition: pulpal and restorative considerations. Dent Traumatol 2002 Jun;18:103-115.

7. Farik B, Munksgaard EC, Andreasen JO, Kreiborg S. Fractured teeth bonded with dentin adhesives with and without unfilled resin. Dent Traumatol 2002 Apr;18(2):66-69.
8. Tennery NT. The fractured tooth reunited using the acid-etch bonding technique. Tex Dent J 1978 Aug;96(8):16-17.

9. Starkey PE. Reattachment of a fractured fragment to a tooth-a case report. J Ind Dent Assoc 1979 Sep-Oct;58(5):37-38.

10. Maia EA, Baratieri LN, de Andrada MA, Monteiro S Jr, de Araújo EM Jr.. Tooth fragment reattachment: fundamentals of the technique and the case reports. Quintessence Int 2003 Feb;34(2):99-107.

11. Lehl G, Luthra R. Reattachment of fractured fragments of maxillary central incisors--report of a case. J Indian Soc Pedod Prev Dent 2004 Jun;22(2):54-55.

12. Hegde RJ. Tooth fragment reattachment-an esthetic alternative: report of a case. J Indian Soc Pedod Prev Dent 2003 Sep;21(3):117-119.

13. Saha SG, Saha MK. Management of a fractured tooth by fragment reattachment-a case report. International Journal of Dental Clinics 2010;2(2):43-47.

14. Chu FC, Yim TM, Wei SH. Clinical considerations for reattachment of tooth fragments. Quintessence Int 2000 Jun;31(6): 385-391.

15. Hamilton FA, Hill FJ, Hollway PJ. An investigation of dentoalveolar trauma and its treatment in an adolescent population. Part 1: The prevalence and incidence of injuries and the extent and adequacy of treatment received. Br Dent J $1997 \mathrm{Feb}$ 8;182(3):91-95.

16. Andreasen JO, Ravn JJ. Epidemiology of traumatic dental injuries to primary and permanent teeth in a Danish population sample. Int J Oral Surg 1972;1(5):235-239.

17. Petti S, Tarsitani G. Traumatic injuries to anterior teeth in Italian schoolchildren: prevalence and risk factors. Endod Dent Traumatol 1996 Dec;12(6):294-297.

18. Andreasen JO, Andreasen FM. Crown-root fractures. In: Andreasen JO, Andreasen FM editors. Textbook and color atlas of traumatic injuries to the teeth. 3rd ed. 1994. p. 275-277.

19. Mazumdar P, Maiti A, Maity I, Das UK. A case report on management of complex crown fracture by non surgical endodontic treatment and fragment reattachment-a novel approach. International Journal of Advanced Research 2016;4(3):1370-1375.

20. Grossmann Y, Araúz-Dutari J, Chogle SM, Blatz MB, Sadan A. A conservative approach for the management of a crown-root fracture. Quintessence Int 2006 Nov-Dec;37(10):753-759.

21. Brown GJ, Welbury RR. Root extrusion a practical solution in complicated crown-root incisor fractures. Br Dent J 2000 Nov 11;189(9):477-478.

22. Murchison DF, Burke FJ, Worthington RB. Incisal edge reattachment; indications for use and clinical technique. Br Dent J 1999 Jun 26;186(12):614-619.

23. Londhe SM, Garge HG, Sudeep S. Reattachment of crown fragment for immediate esthetics. Med J Armed Forces India 2008 Oct;64(4):387-388.

24. Amir E, Bar-Gil B, Sarnat H. Restoration of fractured immature maxillary central incisors using the crown fragments. Pediatr Dent 1986 Dec;8(4):285-288.

25. Taguchi CM, Bernardon JK, Zimmermann G, Baratieri LN. Tooth fragment reattachment: a case report. Oper Dent 2015 May-Jun;40(3):227-34. 